\title{
Hourly resolved cloud modification factors in the ultraviolet
}

\author{
H. Staiger ${ }^{1}$, P. N. den Outer ${ }^{2}$, A. F. Bais ${ }^{3}$, U. Feister ${ }^{4}$, B. Johnsen ${ }^{5}$, and L. Vuilleumier ${ }^{6}$ \\ 1, ${ }^{*}$ German Meteorological Service, Freiburg, Germany \\ ${ }^{2}$ National Institute for Public Health and the Environment, Bilthoven, The Netherlands \\ ${ }^{3}$ Aristotle University, Thessaloniki, Greece \\ ${ }^{4}$ German Meteorological Service, Lindenberg, Germany \\ ${ }^{5}$ Norwegian Radiation Protection Authority, Oesteraas, Norway \\ ${ }^{6}$ Federal Office of Meteorology and Climatology MeteoSwiss, Payerne, Switzerland \\ *emeritus
}

Received: 4 December 2007 - Published in Atmos. Chem. Phys. Discuss.: 8 January 2008

Revised: 26 March 2008 - Accepted: 11 April 2008 - Published: 9 May 2008

\begin{abstract}
Cloud impacts on the transfer of ultraviolet (UV) radiation through the atmosphere can be assessed by using a cloud modification factor (CMF). CMF, which is based on total global solar irradiation (SOL_CMF), has proved to be a solid basis to derive CMFs for the UV radiation (UV_CMF). This is an advantage, because total global irradiance, the basis for SOL_CMF, is frequently measured and forecasted by numerical weather prediction systems and includes all relevant effects for radiation transmission, such as cloud optical depth, different cloud layers, multiple reflection, as well as the distinct difference as to whether the solar disc is obscured by clouds or not. In the UV range clouds decrease the irradiance to a lesser extent than in the visible and infrared spectral range. Thus the relationship between CMFs for solar radiation and for UV-radiation is not straight forward, but will depend on whether, for example, the solar zenith angle (SZA) and wavelength band or action spectrum in the UV have been taken into consideration. Den Outer et al. provide a UV_CMF algorithm on a daily basis, which accounts for these influences. It requires as input a daily SOL_CMF and the SZA at noon. The calculation of SOL_CMF uses the clear-sky algorithm of the European Solar Radiation Atlas to account for varying turbidity impacts. The algorithm's capability to derive hourly UV_CMFs based on the SZA at the corresponding hour and its worldwide applicability is validated for erythemal UV using observational data retrieved from the databases of the COST-Action 726 on "Long-term
\end{abstract}

Correspondence to: H. Staiger

(henning.staiger@gmx.de) changes and climatology of UV radiation over Europe" and the USDA UVB Monitoring Program. The clear-sky part of the models has proved to be of good quality. Accumulated to daily doses it forms a tight cluster of points to the highest measured daily sums. All sky model performances for hourly resolution are shown to be comparable in accuracy with the well performing daily models of the COST-726 model intercomparison.

\section{Introduction}

Clouds may have a dramatic effect on the ultraviolet (UV) and global solar radiation reaching the earth surface, ranging from almost complete extinction under heavy thunderstorms to enhancements of a factor of 2 or more in the case of global solar radiation and up to factors of around 1.4 for UV. Compared to the other UV irradiation determining factors, such as total ozone column (TOC), aerosols and ground albedo, the cloud effects are not as well modelled from first principals. This can be attributed to the intrinsic difficulties in determining cloud characteristics (Calbo et al., 2005). UV, short- and long-wave radiation are affected by cloud cover, as well as cloud optical thickness and cloud-type determined by cloudtop height, water content, and cloud droplet size distribution (Kuchinke and Nunez, 1999, Chen et al., 2000, Josefsson and Landelius, 2000, Cede et al., 2004), whereas cloud-type variations can be as important as cloud cover in the actual radiation field.

Spinhirne and Green (1978) prove by radiative transfer theory that the relative influence of cloud layers on UV and

Published by Copernicus Publications on behalf of the European Geosciences Union. 
Table 1. Information on location, and instruments of sites, that have provided measured hourly UV Index and ancillary input for modelling. Data for Bergen, Potsdam, Davos, and Thessaloniki have been retrieved from the COST-726 database, those for the Everglades and Lauder from the database of the USAD UV-B Monitoring and Research Program.

\begin{tabular}{|c|c|c|c|c|c|c|c|}
\hline Site & $\begin{array}{l}\text { Institute } \\
\text { Country }\end{array}$ & $\begin{array}{l}\text { Location } \\
\text { Altitude }\end{array}$ & $\begin{array}{l}\text { Year } \\
\text { meas. }\end{array}$ & $\begin{array}{l}\text { Instrument } \\
\text { Erythemal UV }\end{array}$ & $\begin{array}{l}\text { Calibration } \\
\text { (traceable to) }\end{array}$ & $\begin{array}{l}\text { UV } \\
\text { Albedo }\end{array}$ & $\begin{array}{l}\text { Total } \\
\text { ozone }\end{array}$ \\
\hline Bergen & NRPA Norway & $\begin{array}{l}60.38^{\circ} \mathrm{N} \\
5.33^{\circ} \mathrm{E} 45 \mathrm{~m}\end{array}$ & $1999+2002$ & GUV, SN 9270. & $\begin{array}{l}\text { NRPA travelling standard GUV. } \\
\text { Johnsen et al. (2002). } \\
\text { Paulsson and Wester (2006). }\end{array}$ & $\begin{array}{l}3 \% \text { and via } \\
\text { snow depth. }\end{array}$ & TOMS. \\
\hline Potsdam & DWD Germany & $\begin{array}{l}52.36^{\circ} \mathrm{N} \\
13.08^{\circ} \mathrm{E} 107 \mathrm{~m}\end{array}$ & 2002 & $\begin{array}{l}\text { Bentham DM150 } \\
\text { double } \\
\text { monochromator + } \\
\text { CIE (1987). }\end{array}$ & $\begin{array}{l}\text { lamps FEL } 1000 W \text { type by PTB, } \\
\text { Germany. }\end{array}$ & $\begin{array}{l}3 \% \text { and via } \\
\text { snow depth. }\end{array}$ & ground based. \\
\hline Thessaloniki & AUTH Greece & $\begin{array}{l}40.63^{\circ} \mathrm{N} \\
22.96^{\circ} \mathrm{E} 60 \mathrm{~m}\end{array}$ & $1999+2002$ & YES UVB-1. & Bais et al. (2001). Garane et al. (2006). & $3 \%$. & ground based. \\
\hline Everglades & $\begin{array}{l}\text { Beard Res. Centre } \\
\text { Florida }\end{array}$ & $\begin{array}{l}25.38^{\circ} \mathrm{N} \\
80.68^{\circ} \mathrm{W} 0 \mathrm{~m}\end{array}$ & 2005 & YES UVB-1. & NIST. USAD UV-B Monitoring. & Tanskanen (2004). & TOMS. \\
\hline Lauder & NIWA New Zealand & $\begin{array}{l}45.03^{\circ} \mathrm{S} \\
169.68^{\circ} \text { E } 370 \mathrm{~m}\end{array}$ & 2004-2005 & YES UVB-1. & NIST. USAD UV-B Monitoring, NDSC. & Tanskanen (2004). & TOMS. \\
\hline
\end{tabular}

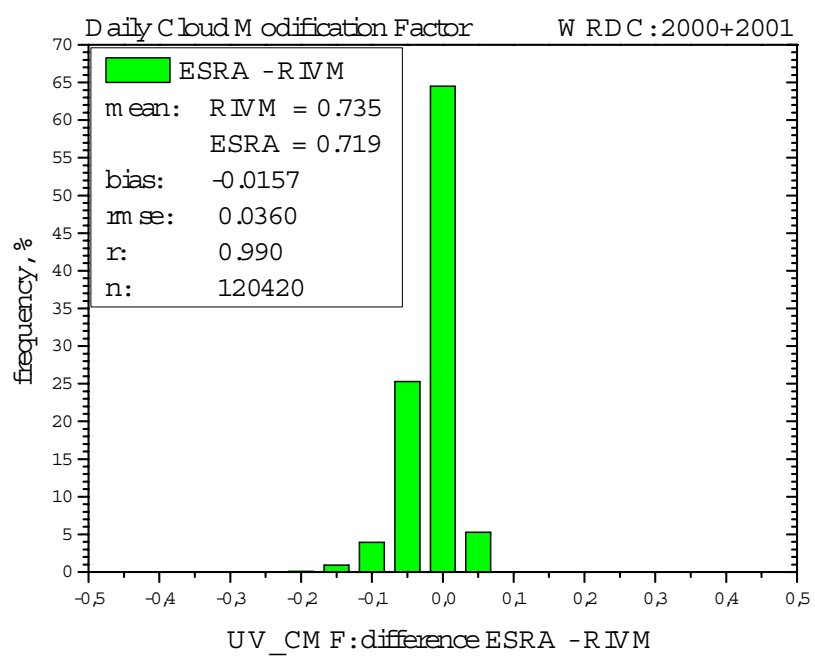

Fig. 1. Distribution of the difference of daily UV Cloud Modification Factors (UV_CMF) modelled based on the algorithm of the European Solar Radiation Atlas (ESRA) and the Netherlands National Institute for Public Health and the Environment (RIVM) to predict total global irradiation. Data are from 183 European sites and include measurements from 2000 and 2001.

total global radiation is dependent primarily on the interaction of the cloud layer with the surrounding atmosphere and the underlying surface, and that in general, increasing cloud thickness decreases UV transmission to a lesser degree than transmission in the visible spectral range, whereas variations in cloud height and surface albedo result in only small changes of the ratio of UV to solar energy flux transmission (proved for wavelengths greater than $300 \mathrm{~nm}$, a maximum surface albedo of $45 \%$ in the UV, and $75 \%$ in the visible). For extreme UV surface albedos, e.g. in Antarctica (Nichol et al., 2003), the ratio may become sensitive to the surface albedo. Furthermore, the ratio of total transmission of UV and global solar radiation through a cloud layer depends on the solar zenith angle (SZA). A wavelength dependence on the cloud effects in the UV region has been shown by measurements (Seckmeyer et al., 1996) and has been physically interpreted by radiative transfer modelling (Kylling et al., 1997). Cloud induced scattering coupled with molecular or particulate absorption can result in a pronounced wavelength dependence of cloud attenuation (Mayer et al., 1998). Erlick et al. (1998) have examined the competing influences of clouds and aerosols. When clouds are superimposed on an aerosol profile, than the wavelength dependence is dominated by the effect of the cloud droplets if the optical depth of the aerosols is less than that of the cloud.

Cloud effects on the transfer of radiation can be assessed by using the cloud modification factor (CMF), generally defined as the ratio between the irradiance under the cloudy sky and the irradiance for the same atmosphere but for cloud-free conditions. The first is either measured or modelled, while the latter is typically modelled. Usually, a CMF in one wavelength regime that is easily measured or modelled is translated to a CMF in the other wavelength regime of interest. A CMF includes effects as multiple reflection between cloud layers, and/or reflection between the sides of the clouds in case of a partly cloudy sky, as well as the distinct difference as to whether the solar disc is obscured by clouds or not. Hence, CMF is not a pure measure of cloud transmittance. Den Outer et al. (2005) have investigated the effects of clouds on UV and total global radiation in the Netherlands based on measured daily erythemally effective UV doses and daily sums of total global irradiance. They developed an algorithm relating the daily CMF in the UV to that in the visible using the SZA at local noon to tune this relationship. Ad- 

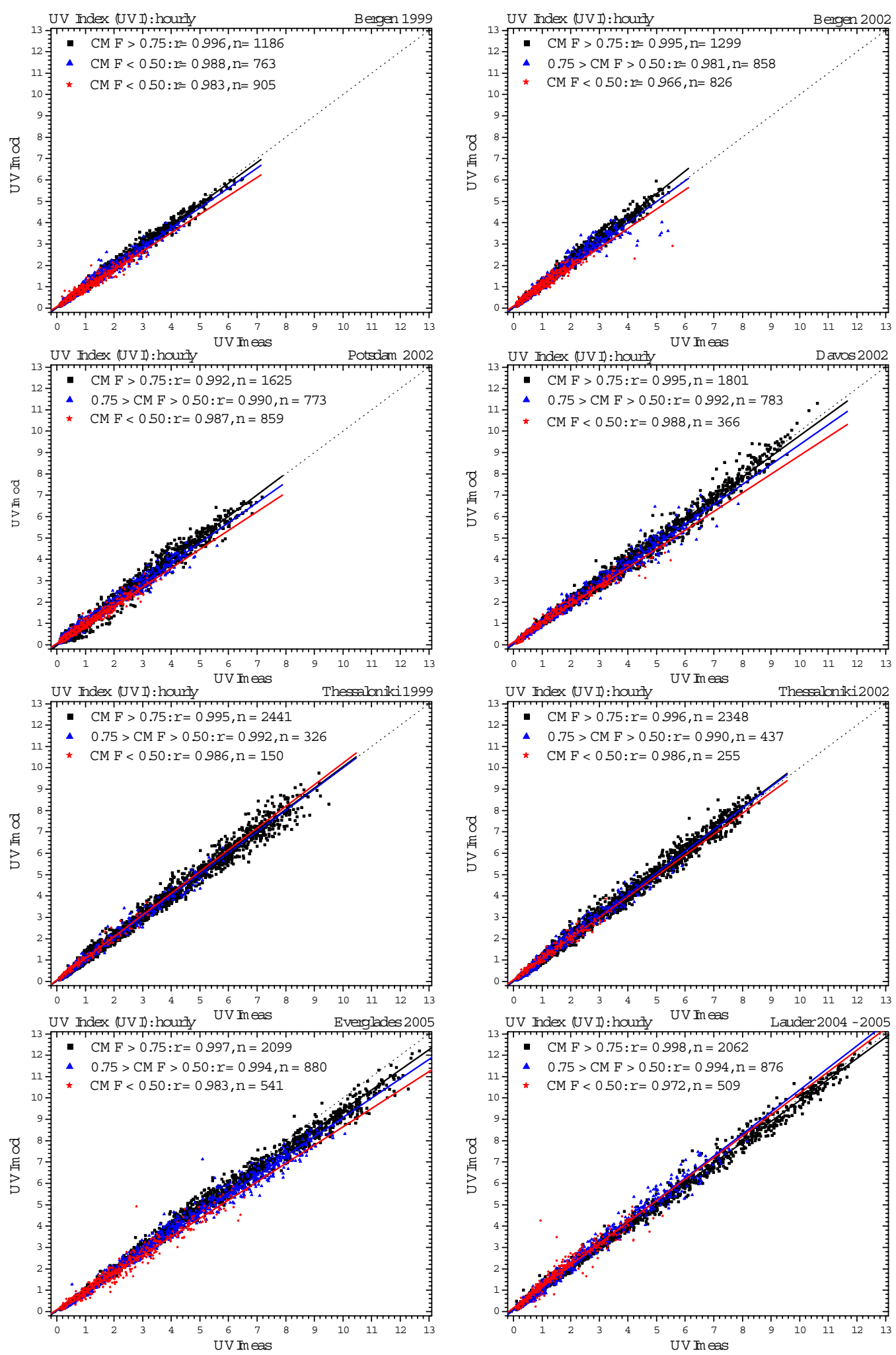

Fig. 2. Scatter plots of measured (UVImeas) and modelled UV Index (UVImod) and regression analysis for 3 ranges of Cloud Modification Factors (CMF): Bergen 1999+2002, Potsdam 2002, Davos 2002, Thessaloniki 1999 + 2002, Everglades 2005, and Lauder 2005. 


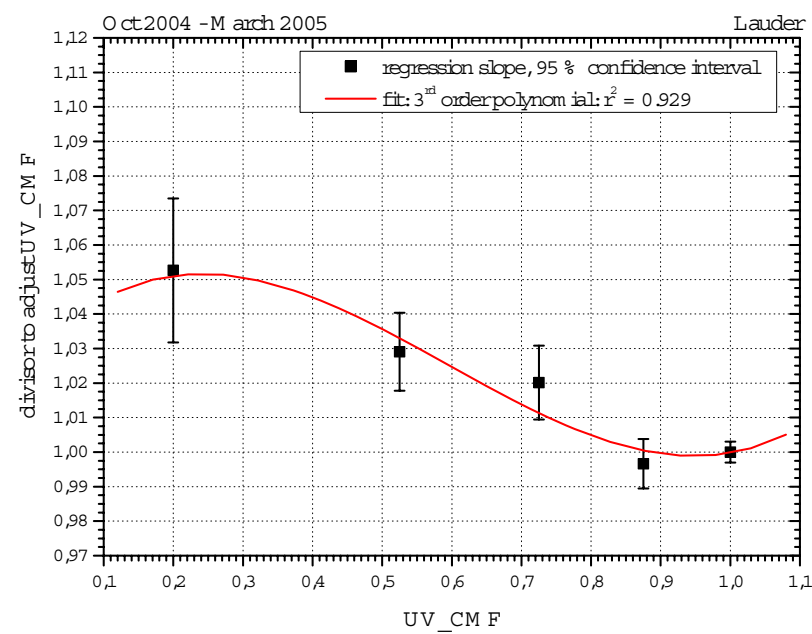

Fig. 3. Divisor to adjust modelled hourly UV Cloud Modification Factors (UV_CMF) by applying the algorithm of the Netherlands National Institute for Public Health and the Environment (RIVM) originally derived for daily sums.

ditionally, it was shown that this relationship also depends on the wavelength ranges considered in the UV. This algorithm is conform to the theoretical requirements (wavelength and SZA dependence) and is shown to be a generic approach, i.e. must not be adjusted for changing locations.

Applications require more often a higher temporal resolution than one day. This study validates the applicability of the algorithm of den Outer et al. (2005) on an hourly base using observational data from four European sites, and two sites representing subtropical to tropical conditions and the southern hemisphere. The European data-base provides only erythemally weighted UV. Thus, the validation is restricted to UV_CMF applied to erythemal UV.

\section{Observational data}

The database of COST-Action 726 on "Long-term changes and climatology of UV radiation over Europe" (http://www. cost726.org) provides measured hourly erythemally (CIE, 1987) effective UV at 4 European sites (Bergen, Potsdam, Davos, Thessaloniki) between 60 and $40^{\circ} \mathrm{N}$, allowing comparison with modelled UV. Measured erythemal UV and total global radiation from the Everglades, Florida, and Lauder, New Zealand, were downloaded from the database of the USDA UVB Monitoring and Research Program (http://uvb. nrel.colostate.edu/UVB/). The Everglades represent subtropical to tropical conditions, and Lauder pristine mid latitude conditions of the southern hemisphere. As ancillary input with a temporal resolution of $1 \mathrm{~h}$, total global radiation is available for all sites. Table 1 provides information on the sites, their location, period with observational data, instruments and their calibration used to determine erythemal UV irradiation, and further ancillary data as albedo and groundbased measured or TOMS (http://toms.gsfc.nasa.gov/ozone/ ozone.html) derived daily values of TOC, respectively.

If snow depth is available it is recorded daily at 06 UTC. Snow depth enables the calculation of the effect of snow cover on the regional UV surface albedo. For Potsdam, ancillary information is available for 1999 too and enables the modelling of hourly UVIs. However, UV observational data are provided only in the form of daily erythemal UV doses, whereas for 2002 measured erythemal UV in hourly resolution is additionally provided.

At Davos snow depth is recorded at the site itself and at the high altitude site Weissfluhjoch, $2540 \mathrm{~m}$ a.s.l., in the vicinity of Davos (horizontal distance less than $4 \mathrm{~km}$ ). We verified that the increase in regional albedo, due to snow at the site and/or on the surrounding mountains, is better represented by the snow depths at Weissfluhjoch compared to a weighted average calculated from the provided snow depths of Davos and of Weissfluhjoch. For reasons given by Lindfors and Vuilleumier (2005), the single scattering albedo (SSA) derived by the Global Aerosol Data Set, GADS (Koepke et al., 1997), appears to be too low for an inner alpine valley site which is clearly in contrast to the lowlands covered by the $5^{\circ} \times 5^{\circ}$ spatially resolved GADS. Thus, for modelling purposes, the required SSA is set at 0.9653 for summer and winter according to the aerosol type "continental clear (cc)".

The COST-726 modelling exercise (Koepke et al., 2006) has revealed that the SSA retrieved from GADS is too high for Thessaloniki, decisively influenced by urban aerosols. Thus, the SSA is fixed at 0.83 based on Bais et al. (2005).

\section{Modelling hourly erythemally effective UV}

Modelling of hourly erythemally effective UV is based on DWD's method for UV Index forecasting (Staiger and Koepke, 2005). It uses lookup tables to calculate a so-called large-scale UV Index, LS_UVI, depending on SZA, TOC, the month of the year, and 10 zonal climatic belts between the South and North Poles, cli_belt. It is valid for mean sea level, clear-sky, a UV surface albedo of 3\%, the aerosol type "continental average" with an aerosol optical depth, AOD, at 550 $\mathrm{nm}$ of 0.20 , and a SSA at $300 \mathrm{~nm}$ of 0.9127 . The dependencies on months and climatic belts account for seasonal and regional profiles of ozone, temperature, and pressure. This assures that the impact of deviations between actual and climatological profiles on clear-sky irradiances is less than 3\% (Schwander et al., 1997, Reuder and Schwander, 1999). The UV Index, UVI, for current atmospheric conditions and the site altitude is calculated by adjusting LS_UVI by factors accounting for AOD and SSA, F_aod_ssa, the altitude effect, F_ae, the UV surface albedo, F_alb, and for cloud modification, UV_CMF: 

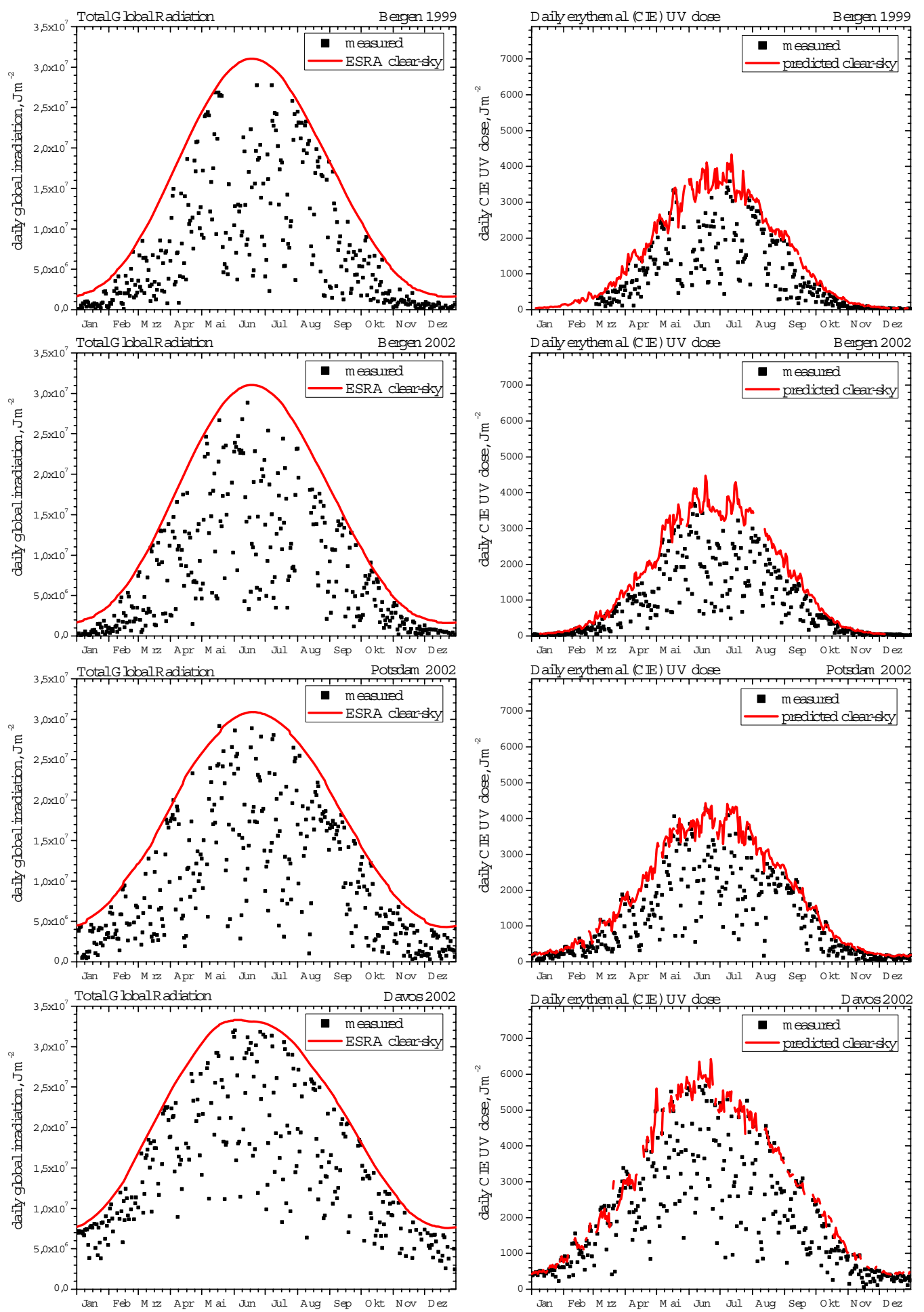

Fig. 4a. Daily global irradiation (left) and daily erythemal UV doses (right). Measured data were integrated from hourly observations and are indicated by black squares. Clear-sky model values are indicated by red lines: Bergen 1999 and 2002, Potsdam 2002, and Davos 2002. 

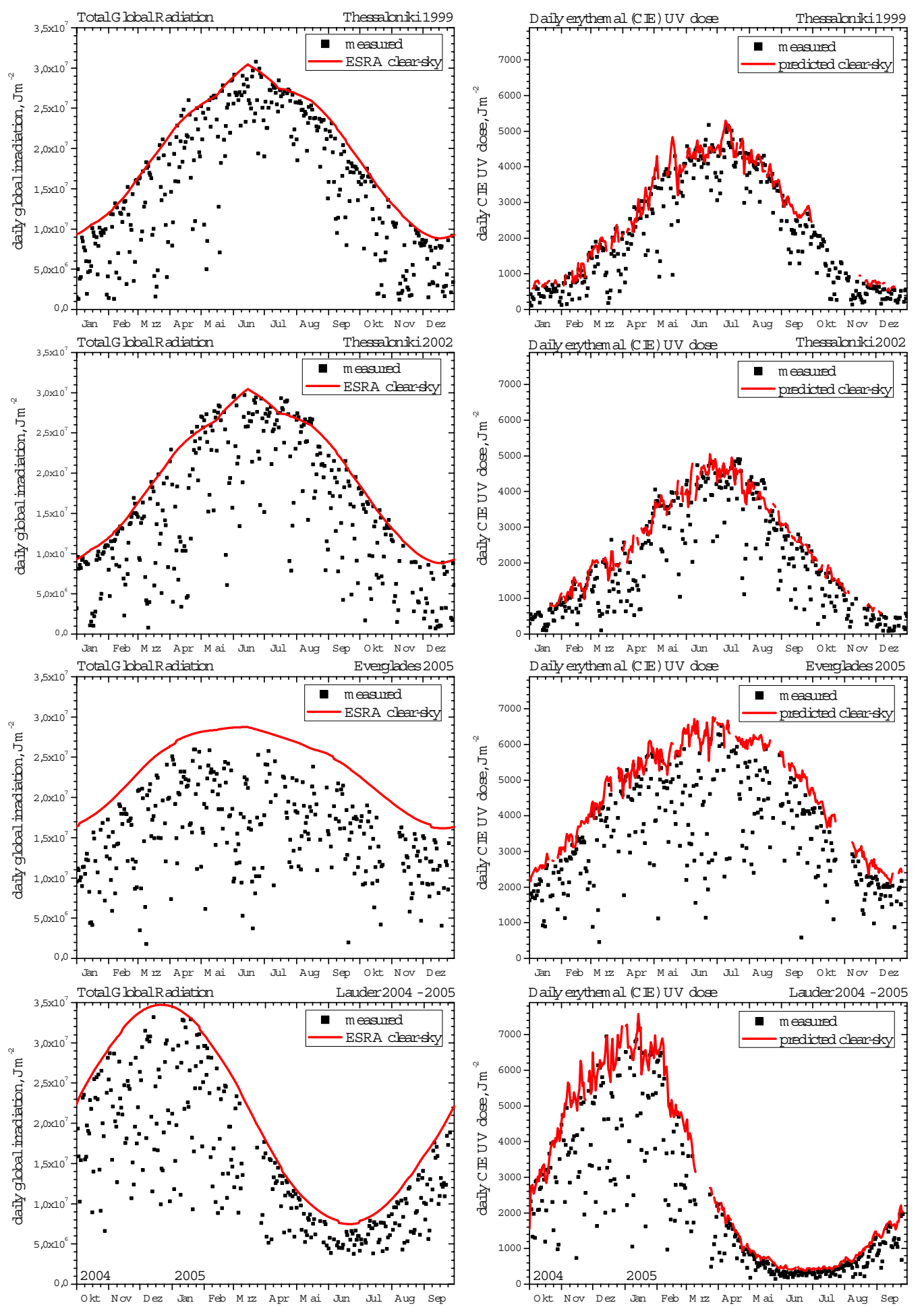

Fig. 4b. As Fig. 4a: Thessaloniki 1999 and 2002, the Everglades 2005, and Lauder 2005. 
Table 2. Summarising statistics of measured and modelled hourly UV Index (UVI) for all effective atmospheric conditions (bias see Table 3, lines absolute differences).

\begin{tabular}{|c|c|c|c|c|c|c|c|c|c|c|}
\hline Site & year & pairs & $\begin{array}{l}\text { average } \\
\text { measured } \\
\text { UVI }\end{array}$ & $\begin{array}{l}\text { std dev. } \\
\text { measured } \\
\text { UVI }\end{array}$ & $\begin{array}{l}\text { average } \\
\text { modelled } \\
\text { UVI }\end{array}$ & $\begin{array}{l}\text { std dev. mod. } \\
\text { modelled } \\
\text { UVI }\end{array}$ & $\begin{array}{l}\text { root mean } \\
\text { square error } \\
\text { UVI }\end{array}$ & $\begin{array}{l}\text { correlation } \\
\text { coefficient }\end{array}$ & $\begin{array}{l}\text { regression } \\
\text { constant } \\
\text { UVI }\end{array}$ & $\begin{array}{r}\text { regression } \\
\text { slope }\end{array}$ \\
\hline Bergen & 1999 & 2860 & 1.206 & 1.209 & 1.165 & 1.164 & 0.151 & 0.993 & 0.012 & 0.957 \\
\hline Bergen & 2002 & 3010 & 1.098 & 1.096 & 1.143 & 1.144 & 0.257 & 0.975 & 0.026 & 1.018 \\
\hline Potsdam & 2002 & 3257 & 1.467 & 1.446 & 1.430 & 1.441 & 0.198 & 0.991 & -0.019 & 0.988 \\
\hline Davos & 1999 & 2868 & 2.480 & 2.347 & 2.380 & 2.242 & 0.321 & 0.992 & 0.030 & 0.948 \\
\hline Davos & 2002 & 2950 & 2.456 & 2.305 & 2.391 & 2.239 & 0.258 & 0.994 & 0.018 & 0.966 \\
\hline Thessaloniki & 1999 & 2917 & 2.494 & 2.265 & 2.529 & 2.281 & 0.228 & 0.995 & 0.029 & 1.003 \\
\hline Thessaloniki & 2002 & 3130 & 2.359 & 2.106 & 2.396 & 2.152 & 0.208 & 0.996 & -0.004 & 1.018 \\
\hline Everglades & 2005 & 3560 & 3.518 & 2.965 & 3.274 & 2.768 & 0.424 & 0.995 & 0.005 & 0.929 \\
\hline Lauder & 2005 & 3460 & 2.353 & 2.644 & 2.406 & 2.603 & 0.212 & 0.997 & 0.097 & 0.981 \\
\hline total & & 28012 & 2.185 & 2.280 & 2.148 & 2.214 & 0.265 & 0.994 & 0.039 & 0.965 \\
\hline
\end{tabular}

$\mathrm{UVI}(d, t)=$

LS_UVI $(\operatorname{SZA}(d, t), \operatorname{TOC}(d, t)$, month, cli_belt)

$\times$ F_aod_ssa $(\operatorname{AOD}(d, t), \operatorname{SSA}(d, t), \operatorname{SZA}(d, t))$

$\times \mathrm{F} \_$ae $(\operatorname{ALT}, \operatorname{AOD}(d, t), \operatorname{SSA}(d, t), \operatorname{SZA}(d, t))$

$\times$ F_alb $(\operatorname{ALB}(d, t), \operatorname{ALT}, \operatorname{AOD}(d, t), \operatorname{SSA}(d, t), \operatorname{SZA}(d, t))$

$\times U_{V}$ CMF $\left(\operatorname{SOL} \_C M F(d, t), \operatorname{SZA}(d, t)\right)$

ALT indicates the altitude a.s.1., ALB the UV surface albedo, SOL_CMF the cloud modification factor in total global irradiance, $d$ the date, and $t$ the time of day. The lookup tables and the factors are calculated by applying STAR (Ruggaber et al., 1994) in its neural network version (Schwander et al., 2001). STAR is a one-dimensional multi-scattering model allowing a detailed description of the atmospheric parameters and has been tested with good results (Koepke et al., 1998).

The albedo of the soil is low in the UV compared to that in the visible spectral range. An essential exception is snow that also increases albedo dramatically in the UV. Thus $F_{-} a l b$ is calculated based on the algorithm of Schwander et al. (1999), depending on snow depth and snow age. Snow age is derived from variations in snow depth within the last 6 days.

AOD and SSA are not available from measurements. Hence, modelling applies seasonal and regional varying climatologies (Staiger and Koepke, 2005). AOD is taken from a March 2000 to February 2005 climatology of MODIS monthly aerosol optical depth at $550 \mathrm{~nm}$ (http:// modis-atmos.gsfc.nasa.gov/MOD08_M3/). SSA applies the semi-annual values of GADS (Koepke et al., 1997) for a relative humidity of $70 \%$. GADS has a spatial resolution of $5^{\circ}$. Section 2 denotes the exceptions concerning Davos and Thessaloniki. Modelling is performed for the centre of the sampling hour of observational data.

\subsection{UV cloud modification factor}

Den Outer et al. (2005) have constructed an algorithm to derive daily erythemally effective UV_CMF from the ratio of daily sums of measured to predicted clear-sky total global irradiation, SOL_CMF. The algorithm is based on spectral measurements of erythemally effective daily UV doses and daily sums of total global irradiation at Bilthoven, Netherlands, for the year 2001. Several improvements have been made (Bordewijk et al., 1995, den Outer et al., 2000 and 2005) finally leading to a parameterisation given by:

$\mathrm{UV} \_\mathrm{CMF}\left(\mathrm{SZA}, \mathrm{SOL} \_\mathrm{CMF}\right)=\frac{1-\left(1+\mathrm{p}(\mathrm{SZA}) \cdot \mathrm{SOL} \_\mathrm{CMF}\right)^{-0.27}}{1-(1+\mathrm{p}(\mathrm{SZA}))^{-0.27}}$

The parameter $p$ controls the curvature of UV_CMF compared to SOL_CMF. It depends exclusively on the daily minimum (noon) SZA. Days sharing the same minimum SZA but at different locations still have the same normalised distribution of SZA in the daily course, hence, the parameterisation is a generic approach. It is constructed so that SOL_CMF=1 implies UV cloudy =UV clear-sky, and also allows for measured total global radiation even exceeding predicted clearsky.

\subsection{Predicted total global radiation clear-sky}

The calculation of a SOL_CMF requires a predicted total global irradiance clear-sky value valid for the same effective atmospheric conditions as measured total global radiation but without clouds. Den Outer et al. (2000) give an algorithm that is based on data series taken at Bilthoven (Netherlands), Garmisch-Partenkirchen (Germany), and Thessaloniki (Greece). The algorithm depends solely on the SZA. In modelling, sun-earth distance oscillations should be taken into account. Due to the exclusive dependency on SZA, the algorithm can be regarded to include a mean annual course of turbidity for Europe. When applied to high altitude sites 

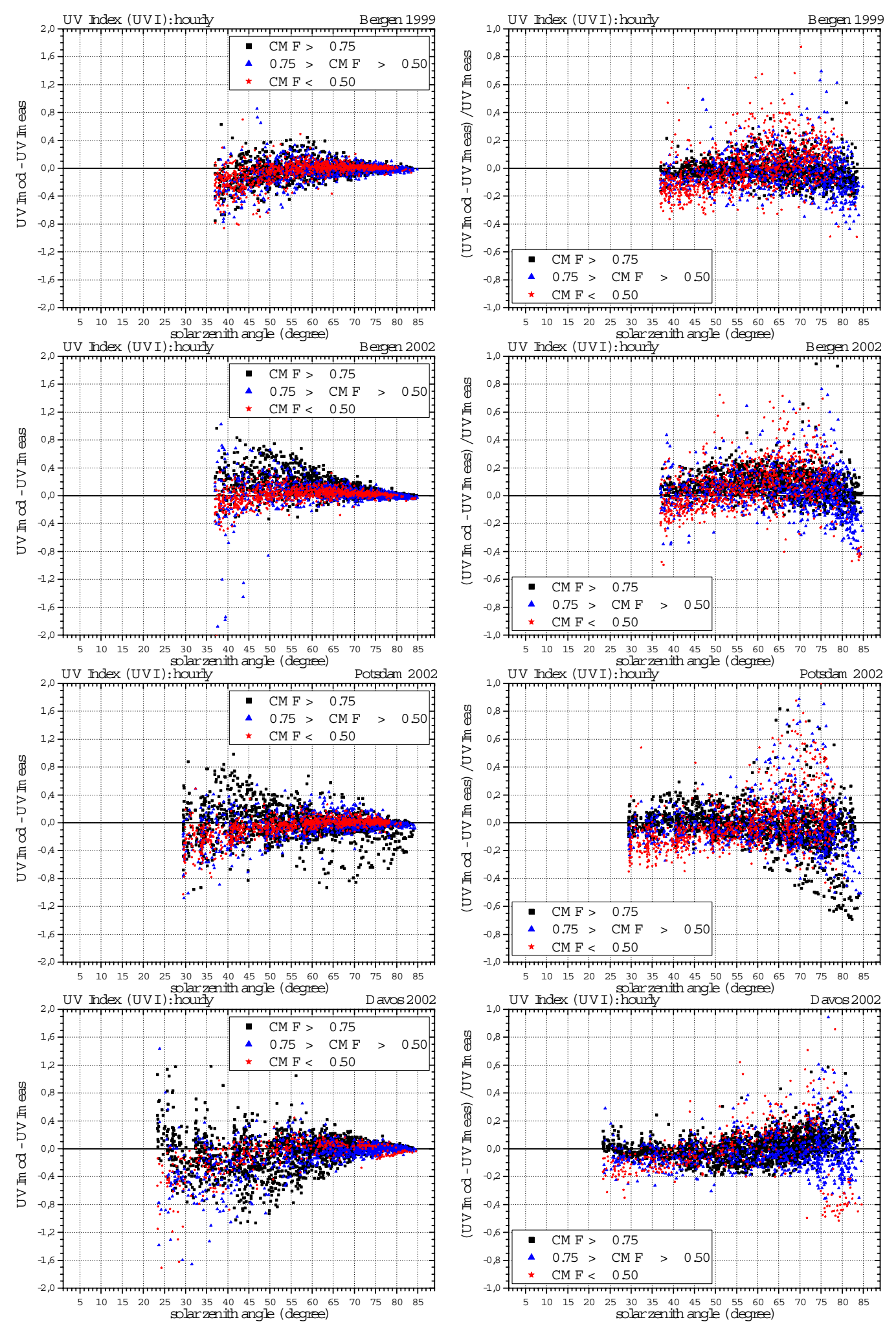

Fig. 5a. (a) Absolute differences of measured minus modelled hourly UV Index (left) and relative difference related to measured values (right), black: UV_CMF $>0.75$, blue 0.75 $>$ UV_CMF $>0.5$, red UV_CMF $<0.5$ : Bergen 1999 and 2002, Potsdam 2002, and Davos 2002. 

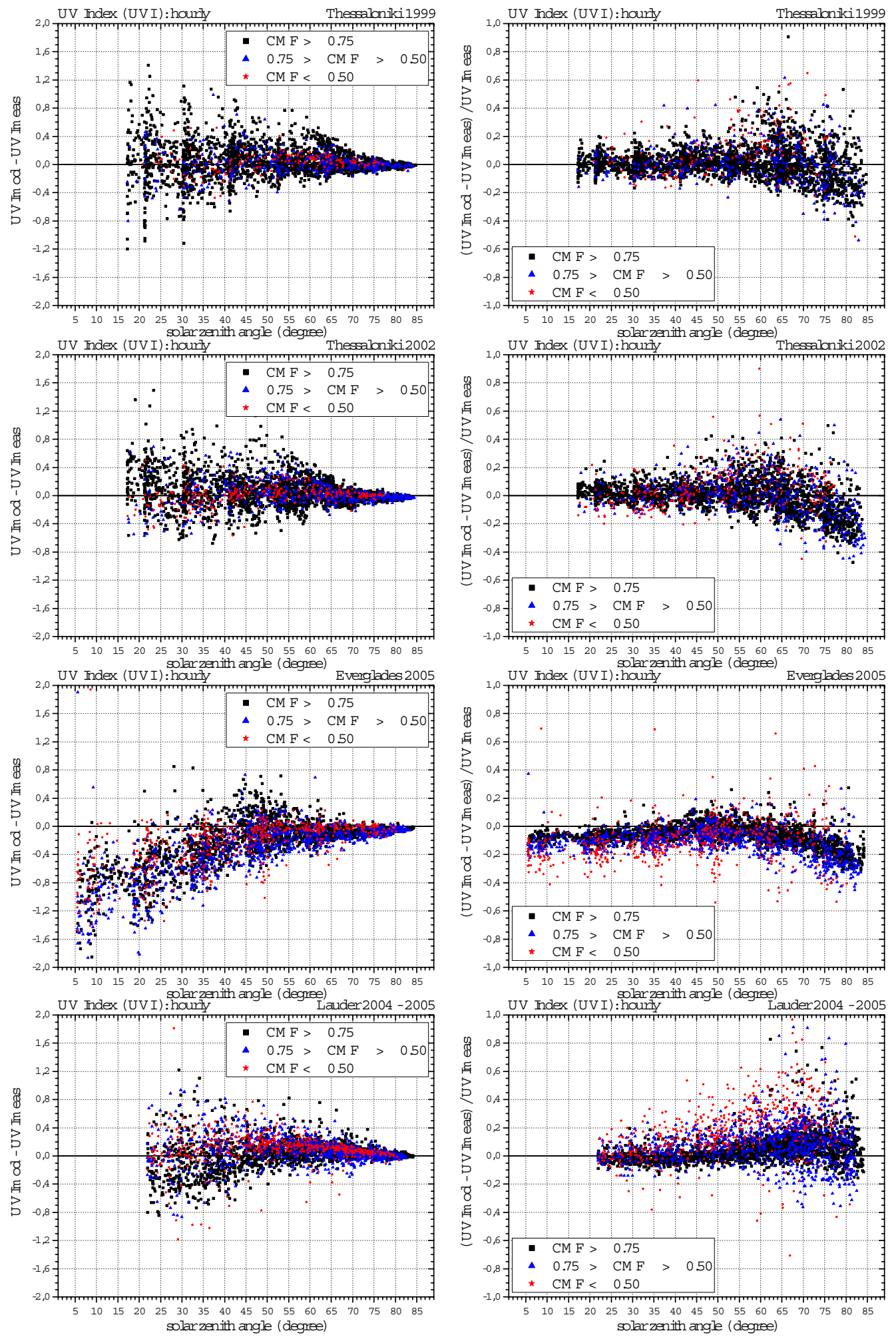

Fig. 5b. As Fig. 5a: Thessaloniki 1999 and 2002, the Everglades 2005, and Lauder 2005. 
a correction should be made, which is approximately 5\% of the correction of UV-irradiance. A more physical approach would be to replace this algorithm with the one used by the European Solar Radiation Atlas, ESRA (Greif and Scharmer, 2000), as given by Rigollier et al. (2000). This algorithm requires a Linke turbidity factor as input. Thus, it allows modelling for sites differing more markedly from mean European conditions in turbidity. The Linke turbidity factor is retrieved from the monthly climatology of world-wide Linke turbidity information (Remund et al., 2003). A linear interpolation dependent on the distance of a day to the middle of the months is performed by applying the turbidity climatology. The frequency distribution of differences in UV_CMF, resulting from both clear-sky algorithms applying Eq. (2) is shown in Fig. 1. It is based on measured daily sums of total global radiation from 183 sites throughout Europe in 2000 and 2001 provided by the WMO World Radiation Data Centre, St. Petersburg, Russia, in the framework of COST-726. The differences can be summarised to be almost unbiased $(-0.016)$ and to show only low scattering (root mean square error, RMSE, of 0.036) compared to the total standard deviation in UV_CMFs $( \pm 0.23)$. The distribution is slightly left-skewed, due to the influence of high mountain sites (9 with altitudes above $1500 \mathrm{~m}$, of these 3 are above $3000 \mathrm{~m}$ ) and in lower parts due to Scandinavian sites showing turbidity less than the European average. This study is based on the version using the ESRA algorithm to predict total global radiation clear-sky to better account for turbidity at the Everglades and Lauder differing from mean European conditions.

\section{Results}

Due to incomplete corrections for the instrument's cosine errors, measurements are typically smaller than the actual irradiance at high SZA. Models such as STAR that apply spherical geometry have been shown to produce higher irradiation for high SZA in particular in the UV-B compared to measurements (van Weele et al., 2000). In the COST-726 comparison of modelled daily erythemal UV doses, the effect could be seen in the relative differences (Koepke et al., 2006) especially for Bergen with a maximum noon SZA of $83^{\circ}$. The logarithm of this relative effect $\Delta p s=$ (spherical-measured) / measured can be fitted by

$$
\begin{aligned}
& \ln (\Delta p s)=1.8912-47.9389 \cdot \mu_{z}+153.5597 \cdot \mu_{z}^{2} \\
& -225.1133 \cdot \mu_{z}^{3}+114.3450 \cdot \mu_{z}^{4}
\end{aligned}
$$

where $\mu_{z}=\cos (\mathrm{SZA})$. Equation (3) is used in hourly resolved clear-sky modelling as a small empirical adjustment for large SZA, to improve the results from the spherical geometry in the model against measured values.

The SZA dependency of parameter $p$, Eq. (2), is originally given for 6 intervals. The $p$ values have been fitted by a second order polynomial enabling the algorithm to be applied in a continuous form, and to extrapolate to SZAs less than the annual minimum at Bilthoven $\left(28.67^{\circ}\right)$ :

$p(\mathrm{SZA})=7.02199-12.73738 \cdot \cos (\mathrm{SZA})+5.72619 \cdot \cos (\mathrm{SZA})^{2}(4)$

A daily UV dose is largely controlled by the hours close to local noon. Hence, it is considered possible to apply Eq. (2) in the calculation of hourly UV_CMFs too, i.e. replacing the daily minimum SZA by that of the corresponding hour. This assumption is validated in the following, and is intended to be a candidate to replace the current empiric cloud modification factors in DWD's UV Index forecasting. It can be anticipated that an hourly application should result in slightly too high UV_CMFs for small SOL_CMFs, because the original daily algorithm has to account for the whole day, including large SZAs (increased $p$ values).

Figure 2 shows scatter plots of modelled versus measured hourly UV Index for the sites. A regression analysis has been performed for three ranges of UV_CMFs. The black symbols and regression lines represent low attenuation of radiation by clouds, $\mathrm{CMF} \geq 0.75$, blue medium, $0.75>\mathrm{CMF} \geq 0.50$, and red strong attenuation, $\mathrm{CMF}<0.50$. Scattering increases only slightly with increasing UVI. The maximum UVI at a site is highest for less clouded conditions and increases for decreasing latitude. However, the maximum UVIs observed for the Everglades and Lauder are comparable due to the smaller sun - earth distance in the southern hemisphere during summer. Despite the difference in latitude between Davos and Thessaloniki, maximum UVIs at the two sites are similar due to the higher altitude of Davos. The less cloudy conditions are represented by a regression slope close to the ideal value of one. Exceptions are the Everglades (due to the overestimated clear-sky total global radiation) and Bergen 2002 because of TOMS: TOMS total ozone values of the year 2002 have an error of $-2 \%$ to $-4 \%$ for latitudes higher than $50^{\circ}$, which is more pronounced in the northern hemisphere.

Unexpectedly, the regression slopes for extremely cloudy conditions are less than those of only slightly cloudy conditions. One of the exceptions is Lauder showing the anticipated slight increase in modelled UVI, with decreasing UV_CMF. The further exception is Thessaloniki 1999, with almost unchanged gradients. This is in contrast to 2002, where there was more frequent advection of less turbid air. This leads to the conclusion: in the pristine air of Lauder there is almost no extinction by aerosol absorption, whereas in Europe there is extinction by aerosol absorption. All-sky modelling applies an AOD climatology that is derived from measurements representing clear-sky conditions. In Europe extinction by aerosol absorption is obviously reduced under more heavily cloudy skies and, in particular, precipitation. The inappropriate model assumptions for Europe cover the obviously small error applying Eq. (2) - originally developed for daily doses - in an hourly resolution. Thus, only the measurements from Lauder enable the effect to be quantified.

The analysis of modelled and measured UVI for differing UV_CMF at Lauder is restricted to the summer season, 
Table 3. Statistics of abs=absolute (modelled minus measured), UVI, and rel=relative (modelled minus measured divided by measured), $\%$, differences of hourly UV Index for all effective atmospheric conditions, and 4 intervals in the solar zenith angle (SZA). $\mathrm{m}=\mathrm{average}$, $\mathrm{s}=$ standard deviation, $\mathrm{BE}=$ Bergen, $\mathrm{PD}=$ Potsdam, $\mathrm{DA}=$ Davos, $\mathrm{TH}=$ Thessaloniki, EV=Everglades, LA=Lauder.

\begin{tabular}{lllrrrrrrrrrr}
\hline & & & BE & BE & PD & DA & DA & TH & TH & EV & LA & total \\
& SZA & & 1999 & 2002 & 2002 & 1999 & 2002 & 1999 & 2002 & 2005 & 2005 & \\
\hline $\mathrm{m}$ & $<30^{\circ}$ & abs & - & - & -0.29 & -0.20 & -0.17 & 0.05 & 0.11 & -0.71 & -0.06 & -0.26 \\
$\mathrm{~s}$ & $<30^{\circ}$ & abs & - & - & 0.35 & 0.61 & 0.51 & 0.41 & 0.34 & 0.42 & 0.39 & 0.54 \\
$\mathrm{~m}$ & $<30^{\circ}$ & rel, \% & - & - & -9.2 & -3.2 & -4.2 & 1.1 & 1.4 & -10.3 & 0.3 & -3.9 \\
$\mathrm{~s}$ & $<30^{\circ}$ & rel, \% & - & - & 11.7 & 15.3 & 9.2 & 6.2 & 6.2 & 8.0 & 9.8 & 10.1 \\
$\mathrm{~m}$ & $30^{\circ}-60^{\circ}$ & abs & -0.08 & 0.09 & -0.04 & -0.22 & -0.14 & 0.05 & 0.06 & -0.18 & 0.07 & -0.04 \\
$\mathrm{~s}$ & $30^{\circ}-60^{\circ}$ & abs & 0.20 & 0.27 & 0.24 & 0.36 & 0.29 & 0.24 & 0.23 & 0.26 & 0.24 & 0.28 \\
$\mathrm{~m}$ & $30^{\circ}-60^{\circ}$ & rel, \% & -3.0 & 5.1 & -2.4 & -4.5 & -2.9 & 2.5 & 2.9 & -4.9 & 5.4 & -0.3 \\
$\mathrm{~s}$ & $30^{\circ}-60^{\circ}$ & rel, \% & 13.4 & 12.1 & 10.6 & 9.1 & 8.6 & 9.0 & 9.7 & 7.8 & 11.0 & 10.9 \\
$\mathrm{~m}$ & $>60^{\circ}$ & abs & -0.01 & 0.04 & -0.03 & 0.01 & 0.01 & 0.02 & -0.01 & -0.08 & 0.05 & 0.00 \\
$\mathrm{~s}$ & $>60^{\circ}$ & abs & 0.06 & 0.07 & 0.13 & 0.09 & 0.09 & 0.11 & 0.09 & 0.08 & 0.08 & 0.10 \\
$\mathrm{~m}$ & $>60^{\circ}$ & rel, \% & -0.2 & 7.0 & -0.8 & 4.2 & 3.1 & 0.2 & -4.5 & -13.2 & 10.8 & 1.4 \\
$\mathrm{~s}$ & $>60^{\circ}$ & rel, \% & 14.1 & 16.2 & 23.7 & 15.7 & 15.6 & 16.2 & 15.1 & 12.7 & 17.9 & 18.0 \\
$\mathrm{~m}$ & $00^{\circ}-90^{\circ}$ & abs & -0.04 & 0.06 & -0.04 & -0.10 & -0.07 & 0.04 & 0.04 & -0.24 & 0.05 & -0.04 \\
$\mathrm{~s}$ & $00^{\circ}-90^{\circ}$ & abs & 0.14 & 0.18 & 0.19 & 0.30 & 0.25 & 0.23 & 0.21 & 0.35 & 0.20 & 0.26 \\
$\mathrm{~m}$ & $00^{\circ}-90^{\circ}$ & rel, \% & -1.4 & 6.3 & -1.7 & 0.0 & 0.2 & 1.3 & -0.4 & -8.8 & 7.8 & 0.3 \\
$\mathrm{~s}$ & $00^{\circ}-90^{\circ}$ & rel, \% & 13.9 & 14.7 & 18.7 & 13.9 & 13.1 & 12.5 & 12.5 & 10.5 & 15.3 & 14.8 \\
\hline
\end{tabular}

Oct 2004 to March 2005, to avoid influences of the potentially slightly overestimated total global radiation clear-sky in winter months. Eq. (2) is developed based on measured daily sums at Bilthoven. Thus, analysis is performed for SZA less than $75^{\circ}$ representing the yearly maximum noon SZA at Bilthoven. With the exception of clear-sky conditions, intervals of UV_CMF are selected to be represented by roughly comparable numbers of cases. For the resulting 5 ranges the ratio of the regression slopes to that of clear-sky conditions has been calculated and fitted. The factor $\mathrm{UV}_{-} \mathrm{CMF}_{\text {dev }}$ describes the overestimation of an hourly UV_CMF by applying Eq. (2) originally developed for daily doses:

$\mathrm{UV}_{\mathrm{C}} \mathrm{CMF}_{\mathrm{dev}}(\mathrm{CMF})=1.0289+0.2056 \cdot \mathrm{CMF}$

$-0.5339 \cdot \mathrm{CMF}^{2}+0.2992 \cdot \mathrm{CMF}^{3}$

CMF=UV_CMF. A modelled hourly UV_CMF can be up to $5 \%$ too high under strong radiation attenuation by clouds, Fig. 3, and can be adjusted for $\mathrm{SZA}<75^{\circ}$ using Eq. (5) as divisor. Figure 3 shows that the fitted curve is within the $95 \%$ confidence interval of the 5 ranges. Nevertheless, the relative wide confidence intervals lead to the conclusion that the function can be only a rough estimate of the effective conditions. Equation (5) is applied as correction for all sites. Because the number of hours with small UV_CMFs is rather low, the mean UVI over all sites is reduced by only $-0.7 \%$ when applying the correction. The reduction is strongest for Bergen with $-1.3 \%$, and lowest for Thessaloniki with $-0.2 \%$.

\section{Model performance}

\subsection{Clear-sky modelling}

The influence of using hourly UV_CMF on modelling results can be separated by first checking the quality of clear-sky modelling. This is performed by integrating the hourly measured all sky and the modelled clear-sky values to a daily dose and plotting them in the yearly course, Fig. 4a and b. The clear-sky sums should then form a tight cluster of points to the highest measured daily sums. Clear-sky daily total global irradiance shows a smooth annual course that is unchanged from year to year, whereas clear-sky daily erythemal UV doses reveal a stronger scattering in the annual course, due to day to day variations in TOC and its distinct differences from year to year, e.g. in Bergen, Fig. 4a. At Bergen the clear-sky total global radiation envelops closely the highest measured daily sums with the exception of the winter months. Surrounding mountains restrict the horizon by up to $10^{\circ}$ at the site, especially in the east. Maximum noon SZAs greater than $80^{\circ}$ can significantly influence the daily sum and are not accounted for in clear-sky modelling. The horizon limitation will affect UV_CMF via SOL_CMF and thus will appear in all sky modelling.

At Potsdam, the envelope of highest measured doses closely matches the clear-sky model results, both for global radiation and $\mathrm{UV}$ radiation.

For Davos only the data set of 2002 is shown, because Davos does not reveal general differences between both years. The modelled clear-sky sums are close to the high- 


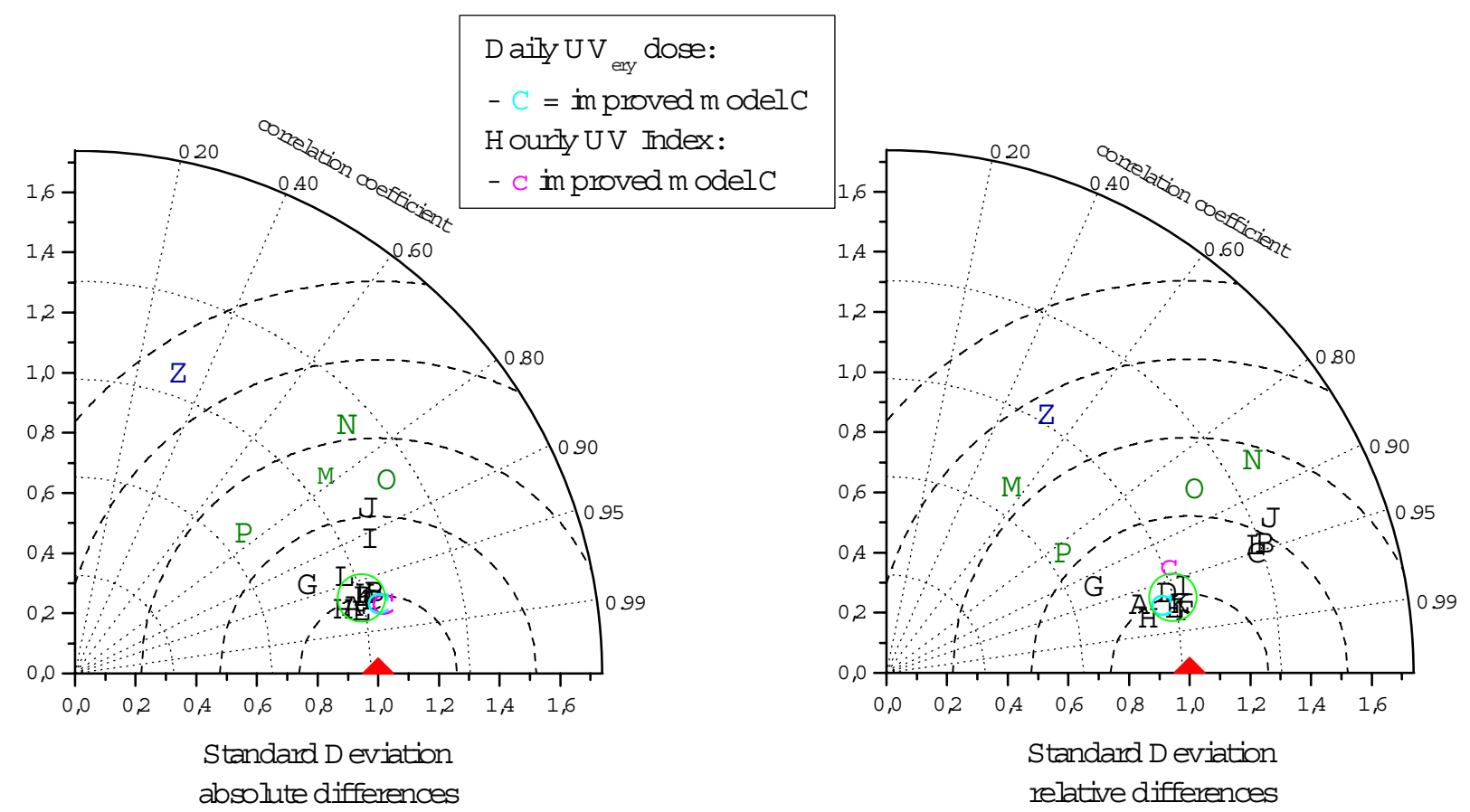

Fig. 6. Taylor diagrams from all available models - measurement pairs of the absolute and relative differences between measured as well as the associated modelled values and smoothed averages of the measurements. Model performance for UV Index using hourly resolved UV_CMFs (magenta coloured "c", six sites, all years) compared to that for daily erythemal effective UV doses of the COST-726 modelling exercise (Koepke et al., 2006). The different models are denoted by the letters A to $\mathrm{P}$, and $\mathrm{Z}$ for persistency. Models A to $\mathrm{K}$ are based on total global radiation for UV_CMF, M to P on sunshine duration. The cyan coloured "C" marks the improved daily erythemal UV doses accumulated from hourly doses in comparison to the black "C" of the old version. It comprises the four European sites, two years, and the days used in the COST-726 exercise. The red triangles mark the measurements and the green circles the group closest to them. Overlapping model letters inside the green circles are: absolute differences: A, B, C, D, E, F, H, K; relative differences: D, E, F, I, K.

est daily doses measured. In the UV, there is a noticeable number of days with slightly higher measured UV doses than modelled clear-sky UV doses, especially in spring. These are affected by snow cover in the mountains influencing the regional albedo and not fully captured by the model. In December and January, the shading effect of surrounding mountains may be derived from the differences in modelled clearsky sums of total global radiation and the upper limit of the measured daily doses.

For Thessaloniki the monthly mean values of the Linke turbidity factor are much higher in May and July ( $\sim 6.0)$ than in June and August ( 4.5). These increases, in conjunction with the summer solstice and the applied linear interpolation, are the reason for the disturbed annual course of the modelled clear-sky daily total global radiation, Fig. 4b. Consequently, for some days in the warm period, the measured total global radiation in Thessaloniki is slightly higher than modelled clear-sky daily sums. The effect in 1999 is minor compared to that in 2002 (period May to August). In the UV, these effects are present too, but less pronounced. Moreover, the number of days with low measured daily sums is greater in summer 2002. This leads to the conclusion that the sum- mer 2002 was more frequently affected by advection of less turbid air.

Considering the Everglades, the modelled daily sums of total global radiation overestimate the highest measured sums, especially in summer, Fig. 4b, although the applied monthly averages of the Linke turbidity factors are the highest within the sites. A reason could be an underestimation of water vapour over the wetlands, where water temperatures are higher than the nearby ocean. By contrast, the modelled clear-sky UV doses represent the highest measured doses.

Modelled clear-sky daily sums of UV, and of total global radiation at Lauder form a tight cluster of points to the respective highest measured daily sums with a tendency of slightly overestimated sums of total global radiation in the southern winter.

\subsection{All-sky modelling}

Clear-sky modelling has proved to be of good quality. Thus, the main uncertainties in modelling will depend on cloud effects. Tables 2 and 3 summarise the comparison of modelled and measured UVI for the individual sites and years. The overall RMSE is 0.27 UVI or $12.1 \%$ related to the mean 
of measurements, Table 2. The bias for the sites in all is -0.04 UV Index or $-1.7 \%$ (see lines of absolute differences in SZA interval $0^{\circ}$ to $90^{\circ}$ in Table 3). Bergen 2002 shows a positive bias, due to TOC from degrading TOMS, the Everglades a negative one, due to overestimated total global radiation clear-sky. The relative RMSE increases with latitude, due to lower absolute values and to an increased likelihood of cloudy conditions. The bias of Bergen 2002 and that of the Everglades contribute to the relative higher RMSE of the sites. The modelling of daily doses for the European sites (Koepke et al., 2006) has resulted in a mean bias of $+1.1 \%$ and a RMSE of $9.8 \%$ of the 7 best performing models. The slightly higher RMSE of UVI compared to that of the daily doses can be attributed to the higher temporal resolution. For Potsdam 2002, empiric hourly UV_CMFs (Staiger et al., 1998) have additionally been calculated based on synoptic cloud observations. The resulting UVI has a bias of -0.02 UV Index and a RMSE of $31.8 \%$, whereas the RMSE applying Eq. (2) for modelling is reduced to $13.5 \%$ for Potsdam, Table 2. Using total global irradiation as an input parameter in determining UV_CMFs has the decisive advantage of taking into account the effects of whether the solar disc is obscured by clouds or not, and of including direct information on cloud optical depth.

\subsubsection{Accuracy}

Figures 5a and $\mathrm{b}$ give the absolute differences (modelled minus measured) in UVI dependent on SZA (left) for cases when measured UVI and modelled clear-sky UVI are greater or equal to 0.10 . The relative differences (right) are related to measured UVI. Again the symbols and their colours distinguish between low (black), medium (blue), and strong (red) radiation attenuation by clouds. The graphs are summarised statistically by Table 3 that provides insight into variations dependent on SZA. The absolute differences are of relevance when considering the essential UV effects. The relative differences consider percentage deviations and thus provide further insight into model quality for low absolute values. Furthermore, they represent the accuracy of modelled UV_CMF, because measured and modelled UVI can be considered as the product of modelled clear-sky UVI and modelled / "measured" CMF, respectively. Uncertainties regarding clear-sky UVI will contribute slightly to the variance.

The scattering in the absolute differences increases with decreasing SZA, i.e. increasing absolute UVI. The relative differences reveal a more or less constant scattering for SZA of less than about $60^{\circ}$. For higher SZA scattering increases with increasing SZA, which may be in parts due to the decreasing absolute values they are related to. The scattering in the relative differences is highest for the sites more frequently influenced by changes in cloudiness, i.e. Bergen, Potsdam, and Lauder. For Bergen 1999, the scattering is somewhat reduced, because UV data for January and February (months with low UVI) are not available. The too highly predicted total global radiation clear-sky for the Everglades results in UV_CMF modelled too low and thus in UVIs, which are too low. Figure 5b depicts underestimated UVI in absolute and relative differences, particularly in summer. Table 3 quantifies the deviations. Under more heavily clouded skies, UVIs for low SZA are slightly underestimated for the European sites, due to aerosol properties applied in modelling, which are unchanged versus clear-sky.

\subsubsection{Taylor diagram}

The modelling performance applying hourly resolved UV_CMF based on Eq. (2) and adjusted using Eq. (5) can be checked versus the results of the COST-726 model intercomparison for daily erythemally effective UV doses (Koepke et al., 2006). In COST-726 this has been done in terms of model to measurement correlation, together with standard deviations of measured and modelled data and displayed in polar coordinates, as proposed by Taylor (2001). The diagram has been developed to visualise the patterns of various simulations of measured data in one diagram. The radial distance is given by the standard deviation of the modelled data normalised to the measured standard deviation, the angular position by the arc-cosine of the correlation coefficient, $r$. Thus, the position of the measured data is given by $r=1$ and the standard deviation 1 , and is indicated by red triangles in Fig. 6. The individual simulation can be evaluated relative to the measurements by the pattern RMSE difference (Taylor, 2001). It is given by the vector from the point of the measurements to that representing the result of one model. The pattern RMSE difference approaches zero as two patterns become more alike. The different models of the COST-726 intercomparison for daily erythemal UV doses are denoted in Fig. 6 by the letters " $A$ " to "P", and " $Z$ " for persistency. Models " $\mathrm{A}$ " to " $\mathrm{K}$ " are based on total global radiation for UV_CMF, "M" to "P" on sunshine duration.

Time series often show a high autocorrelation. In the daily UV doses the autocorrelation is represented by the day of the year (DOY). The dominating effect is the dependence on noon SZA. This is a direct function of DOY. Secondary effects in autocorrelation will be e.g. seasonal variations in total ozone column, and in aerosol optical depth. These can be estimated to yield an influence about one order of magnitude less than the SZA dependence. COST-726 has removed the autocorrelation calculating the residuals between the measured as well as the associated modelled values and smoothed averages of the measurements for each site and each year. The residuals are input to regression analysis. Smoothing applies the method LOWESS, a locally weighting polynomial regression (http://www.itl.nist.gov/div898/handbook/ $\mathrm{pmd} / \mathrm{section} 1 / \mathrm{pmd} 144 . \mathrm{htm})$.

The modelled hourly UVIs for the European sites, including Potsdam 1999, are accumulated to daily doses and displayed in Fig. 6 in complete compatibility to COST-726 by the cyan coloured letter " $C$ ". It represents the improvements 
due to SZA, Eq. (3), and UV_CMF adjustment, Eq. (5), as well as the adaptions in AOD and albedo concerning Davos and Thessaloniki and denoted in Sect. 2. The absolute differences, as well as the relative differences are within the group of the best performing daily models.

The hourly UVIs show autocorrelation due to diurnal and annual variations in SZA. A scatter-gram of measured hourly UVIs against SZA is constructed for each year and each site. Based on the scatter-gram, a smoothed average dependent on SZA is calculated by applying LOWESS. The selected degree of smoothness of the hourly data sets is comparable to that of the daily doses. Calculating the residuals to the smoothed averages removes the autocorrelation due to SZA by a method in full equivalence to the daily doses.

The results for the hourly resolved UVI of the 6 sites and all years are displayed in Fig. 6 (magenta coloured "c") versus the COST-726 performance analysis for daily UV doses. The absolute differences are within the group of the best performing daily models. The relative differences are very close to them. They give an account of increased scattering due to the temporarily higher resolved hourly data.

\section{Conclusions}

Equation (2) has been shown to be applicable in a temporal resolution of one hour. It is a generic approach, i.e. it can be used world-wide, assuming one applies an appropriate algorithm for predicting clear-sky total global irradiances accounting for long-term conditions of turbidity and its seasonal variations at a location. Concerning RMSE and bias the hourly application is comparable to that of daily resolution, for which the algorithm was originally developed. Applying the algorithm in hourly resolved UV_CMFs can strongly reduce RMSE compared to schemes based on cloud cover or sunshine duration, because the SOL_CMF includes information on cloud optical depth and whether the solar disc is obscured by clouds.

Current DWD UVI forecasts apply 6 values of empirical UV_CMFs dependent on forecasted cloudiness in low, middle, and high layers. Numerical weather prediction (NWP) comprises physical parameterisations to calculate surface total global radiation. These parameterisations account for optical properties of forecasted cloudiness in all model layers. Applying NWP surface total global radiation in UVI forecasting via Eq. (2) takes advantage of the higher vertical resolution and the computed radiation transfer in the visible spectral range and thus reduces computational costs by not repeating these highly resolving calculations in the UV. Furthermore, it benefits automatically from each improvement in the parameterisation of radiation transfer and in forecasting cloudiness, e.g. by the introduction of SZA dependent overlapping of cloud layers (Tompkins and Di Guiseppe, 2007), or the treatment of ice cloud optical properties in DWD's NWP operational radiation scheme (Ritter and Geleyn, 1992,
Doms and Schättler, 2003). In future, daily assimilated and forecasted aerosol amounts will be available for several aerosol types, e.g. as result of the EU funded GEMS project (http://www.ecmwf.int/research/EU_projects/GEMS/ index.jsp), and will enable climatologies derived from clearsky conditions to be replaced.

COST-726 is directed toward UV reconstruction. On a European scale it can rely neither on measured daily values of turbidity nor on long-term trends in aerosol properties. However, available measured daily sums of total global irradiance will include deviations from climatological values in the calculated UV_CMF. The relation between UV_CMF and SOL_CMF is functional but not linear. Thus, the modelling of clear-sky total global irradiation and clear-sky UV should rely on comparable assumptions of mean turbidity and its seasonal variations to keep the increments due to aerosols as low as possible.

Acknowledgements. This study has been performed in the framework of the COST-Action 726 on "Long-term changes and climatology of UV radiation over Europe". The measurements from the Everglades, Florida/USA, and Lauder, New Zealand, have been accessed via the database of the USDA UV-B Monitoring and Research Program, Natural Resource Ecology Laboratory, Colorado State University, Fort Collins, Co. 80523. Via COST-726, the WMO World Radiation Data Centre, St. Petersburg, Russia, has made available daily sums of total global irradiation for Europe. Thanks go to the NASA Goddard Space Flight Center for allowing public access to earth probe TOMS/V8, level 3 data of total column ozone.

Edited by: M. Blumthaler

\section{References}

Bais, A., Topaloglou, C., Kazadtzis, S., Blumthaler, M., Schreder, J., Schmalwieser, A., Henriques, D., and Janouch, M.: Report of the LAP/COST/WMO intercomparison of erythemal radiometers, World Meteorological Organization (WMO), 54 pp., Geneva, 2001.

Bais, A. F., Kazantzidis, A., Kazadzis, S., Balis, D. S, Zerefos, C. S., and Meleti, C.: Deriving an effective aerosol single scattering albedo from spectral surface UV irradiance measurements, Atmos. Environ., 39, 1093-1102, 2005.

Bordewijk, J. A., Slaper, H., Reinen, H. A. J. M., Schlamann, E.: Total solar radiation and the influence of clouds and aerosols on the biologically effective UV, Geophys. Res. Lett., 22, 21512154, 1995.

Calbo, J., Pages, D., and Gonzales, J.-A.: Empirical studies of cloud effects on UV radiation: A review, Review of Geophysics 43, RG2002, 1-28, doi: 10.1029/2004RG000155, 2005.

Cede, A., Luccini, E., Nunez, L., Piacentini, R. D., Blumthaler, M., and Herman, J. R.: TOMS-derived erythemal irradiance versus measurements at the stations of the Argentine UV Monitoring Network, J. Geophys. Res., 109, D08109, 1-11, doi: 10.1029/2004JD004519, 2004. 
Chen, T., Rossow, W. B., and Zhang, Y.: Radiative Efects of CloudType Variations, J. Climate, 13, 264-286, 2000.

CIE: A reference action spectrum for ultraviolet induced erythema in human skin. CIE Research Note, CIE Journal 6, 17-22, 1987.

Den Outer, P. N., Slaper, H., Matthijsen, J., Reinen, H. A. J. M., and Tax, R.: Variability of Ground-Level Ultraviolet: Model and Measurement, Radiat. Prot. Dosim., 91, 105-110, 2000.

Den Outer, P. N., Slaper, H., and Tax, R. B.: UV radiation in the Netherlands. Assessing long-term variability and trends in relation to ozone and clouds, J. Geophys. Res., 110, D02203, 1-11, doi: 10.1029/2004JD004824, 2005.

Doms, G., and Schättler, U.: LM-Documentation 2nd version, Part II: Physical Parameterization, 1-133, available at http:// cosmo-model.cscs.ch/public/documentation.htm, 2003.

Erlick, C., Frederick, J. E., Saxena, V. K., and Wenny, B. N.: Atmospheric transmission in the ultraviolet and visible: Aerosols in cloudy atmospheres, J. Geophys. Res. 103, 31 541-31 556, 1998.

Garane, K., Bais, A. F., Kazadzis, S., Kazantzidis, A., and Meleti, C.: Monitoring of UV spectral irradiance at Thessaloniki (19902005): Data re-evaluation and quality control, Ann. Geophys., 24 (12), 3215-3228, 2006.

Greif, J., and Scharmer, K. (ed.): The European Solar Radiation Atlas, Vol. 2: Database, Models and Exploitation Software, École des Mines de Paris, 1-296, France, 2000.

Johnsen, B., Mikkelborg, O., Hannevik, M., Nilsen, L. T., Saxebol, G., and Blaasaas, K. G.: The Norwegian UV Monitoring Network. Period 1995/96 to 2001, Norwegian Radiation Protection Authority, Straalevern Rapport 2002:4, 1-41, 2002.

Joseffson, W., and Landelius, T.: Effect of clouds on UV irradiance: As estimated from cloud amount, cloud type, precipitation, global radiation and sunshine duration, J. Geophys. Res. 105, 4927-4935, 2000.

Koepke, P., Hess, M., Schult, I., and Shettle, E. P.: Global Aerosol Data Set, Max-Planck-Institut für Meteorologie, Report No. 243, 1-44, 1997.

Koepke, P., Bais, A., Balis, D.; Buchwitz, M., De Backer, H., De Cabo, X., Eckert, P., Eriksen, P., Gillotay, D., Heikkilä, A., Koskela, T., Lapeta, B., Litynska, Z., Lorente, J., Mayer, B., Renaud, A., Ruggaber, A., Schauberger, G., Seckmeyer, G., Seifert, P., Schmalwieser, A., Schwander, H., Vanicek, K., and Weber, M.: Comparison of Models Used for UV Index Calculations, Photochem. Photobiol., 67, 657-662, 1998.

Koepke, P., De Backer, H., Bais, A., Curylo, A., Eerme, K., Feister, U., Johnsen, B., Junk, J., Kazantzidis, A., Krzyscin, J., Lindfors, A., Olseth, J. A., den Outer, P., Pribullova, A., Schmalwieser, A. W., Slaper, H., Staiger, H., Verdebout, J., Vuilleumier, L., and Weihs, P.: Modelling solar UV radiation in the past: Comparison of algorithms and input data, P. SOC. PHOTO-OPT. INST. Remote Sensing of Clouds and the Atmosphere XI, 11-14 Sep 2006, Stockholm, Sweden, SPIE 6362, 636215, 1-11, 2006.

Kuchinke, C. and Nunez, M.: Cloud Transmission Estimates of UVB Erythemal Irradiance, Theor. Appl. Climatol., 63, 149-161, 1999.

Kylling, A., Albold, A., and Seckmeyer, G.: Transmittance of a cloud is wavelength-dependent in the UV-range: Phsysical interpretation, Geophys. Res. Lett., 24, 397-400, 1997.

Lindfors, A. and Vuilleumier, J.: Erythemal UV at Davos (Switzerland), 1926 - 2003, estimated using total ozone, sunshine duration, and snow depth, J. Geophys. Res., 110, D02104, 1-15, doi:
10.1029/2004JD005231, 2005.

Mayer, B., Kylling, A., Madronich, S., and Seckmeyer, G.: Enhanced absorption of UV radiation due to multiple scattering in clouds: Experimental evidence and theoretical explanation, J. Geophys. Res. 103, 31 241-31 254, 1998.

Nichol, S. E., Pfister, G., Bodeker, G. E., McKenzie, R. L., Wood, S. W., and Bernhard, G., Moderation of cloud reduction of UV in the Antarctic due to high surface albedo, J. Appl. Meteorol., 42, 1174-1183, 2003.

Paulsson, L. E., and Wester, U.: The Nordic intercomparison of ultraviolet and total ozone radiometers at Tylösand, Sweden, in 2000, Swedish Radiation Protection Authority, SSI Reports, 2006.

Remund, J., Wald, L., Lefevre, M., and Ranchin, T.: Worldwide Linke Turbidity Information. Proceedings of ISES Solar World Congress, 16-19 June 2003, Göteborg, Sweden, CD-ROM published by the International Solar Energy Society, 2003.

Reuder, J. and Schwander, H.: Aerosol effects on UV radiation in nonurban regions. J. Geophys. Res., 104, 4065-4077, 1999.

Rigollier, C., Bauer, O., and Wald, L.: On the Clear Sky Model of the ESRA - European Solar Radiation Atlas - With Respect to the HELIOSAT Method. Sol. Energy, 68, 33-48, 2000.

Ritter, B. and Geleyn, J. F.: A comprehensive radiation scheme for numerical weather prediction models with potential applications in climate simulations, Mon. Weather Rev. 120, 303-325, 1992.

Ruggaber, A., Dlugi, R., and Nakajima, T.: Modelling radiation quantities and photolysis frequencies in the troposphere, J. Atmos. Chem., 18, 171-210, 1994.

Schwander, H., Koepke, P., and Ruggaber, A.: Uncertainties in modeled UV irradiances due to limited accuracy and availability of input data. J. Geophys. Res., 102, 9419-9429, 1997.

Schwander, H., Mayer, B., Ruggaber, A., Albold, A., Seckmeyer, G., and Koepke, P.: Method to determine snow albedo values in the ultraviolet for radiative transfer modelling, Appl. Optics, 38, 3869-3875, 1999.

Schwander, H., Kaifel, A., Ruggaber, A., and Koepke, P.: Spectral radiative transfer modeling with minimized computation time by use of neural-network technique, Appl. Optics, 40, 331-335, 2001.

Seckmeyer, G., Erb, R., and Albold A.: Transmittance of a cloud is wavelength-dependent in the UV-range, Geophys. Res. Lett., 23, 2753-2755, 1996.

Spinhirne, J. D. and Green, A. E. S.: Calculation of the relative influence of cloud layers on received ultraviolet and integrated solar radiation, Atmos. Envrion., 12, 2449-2454, 1978.

Staiger, H., Vogel, G., Schubert, U., Kirchner, R., Lux, G. and Jendritzky, G.: UV Index Calculation by the Deutscher Wetterdienst and Dissemination of UV Index Products. - In WMO: Report on the WMO-WHO Meeting of Experts on Standardization of UV Indices and their Dissemination to the Public. WMO/TDNo. 921: 89-92, 1998.

Staiger, H. and Koepke, P.: UV Index forecasting on a global scale, Meteorol. Z., 14: 259-270, 2005.

Tanskanen, A.: Lambertian Surface Albedo Climatology at $360 \mathrm{~nm}$ from TOMS Data Using Moving Time-Window Technique. In: Proceedings Quadrennial Ozone Symposium, Kos, Greece, 1-8 June 2004, 1159-1160, 2004.

Taylor, K. E.: Summarizing multiple aspects of model performance in a single diagram, J. Geophys. Res., 106, 7183-7192, 2001. 
Tompkins, A. M., Di Giuseppe, F.: Generalizing Cloud Overlap Treatment to Include Solar Zenith Angle Effects on Cloud Geometry, J. Atmos. Sci. 64, 2116-2125, 2007. van Weele, M., Martin, T. J., Blumthaler, M., Brogniez, C., Den Outer, P. N., Engelsen, O., Lenoble, J., Mayer, B., Pfister, G., Ruggaber, A., Walravens, B., Weihs, P., Gardiner, B. G., Gillotay, D., Haferl, D., Kylling, A., Seckmeyer, G., and Wauben, W. M. F.: From model intercomparison toward benchmark UV spectra for six real atmospheric cases, J. Geophys. Res., 105, 49154925, 2000. 